\title{
Pentecostalismos y construcción de identidades sociopolíticas
}

\author{
Nicolás PANOTTOT*
}

\begin{abstract}
Artículo recibido: 22 de enero de 2014
\end{abstract}
Artículo aprobado: 3 de marzo de 2014

Doi: dx.doi.org/10.12804/desafios26.02.2014.03

Para citar este artículo: Panotto, N. (2014). Pentecostalismos y construcción de identidades sociopolíticas. Desafíos, 26 (2), 73-96. doi: dx.doi.org/10.12804/desafios26.02.2014.03

\section{Resumen}

El articulo introduce la noción de identidad desde diversos abordajes actuales — como teorías políticas postestructuralistas y poscoloniales, dentro de la filosofía y de la antropología - y cómo ella posibilita la ampliación del estudio de las dinámicas políticas desde la pluralidad de sujetos sociales contemporáneos, dentro de los cuales se encuentran las comunidades religiosas. Como caso especifico de estudio tomaremos una comunidad neopentecostal en Buenos Aires, el Centro Cristiano Nueva Vida (CCNV), donde analizaremos cómo dicha iglesia construye su identidad sociopolitica desde los procesos que se gestan desde su especificidad religiosa, o sea, sus discursos teológicos, procesos simbólicos, ritos y modalidades institucionales.

Palabras clave: Identidad, pentecostalismo, sujeto, politica, religión.

* Becario del Consejo Nacional de Investigaciones Científicas y Técnicas (CONICET) y doctorando en Ciencias Sociales por la Facultad Latinoamericana de Ciencias Sociales (FLACSO), Buenos Aires, Argentina. Correo electrónico: nicolaspanotto@yahoo.com.ar 


\title{
Pentecostalism and the Construction of Socio-Political Identities
}

\begin{abstract}
This article introduces the notion of identity from various current approaches - such as poststructuralist and postcolonial theories within the area of philosophy as well as anthropology - and how identity, taking into account the plurality of contemporary social subjects such as religious communities, enables the expansion of the study of political dynamics. As a specific case study, a neopentecostal community in Buenos Aires, Centro Cristiano Nueva Vida (CNVC) is selected. The article analyzes how this church builds its socio-political identity in light of its religious specificity: theological discourses, symbolic processes, rituals, and institutional methods.
\end{abstract}

Keywords: Identity, pentecostalism, subject, politics, religion.

\section{Pentecostalismos e construção de identidades sócio-políticas}

\begin{abstract}
Resumo
$O$ artigo introduz a noção de identidade desde diversas abordagens atuais — tais como teorias políticas pós-estruturalistas e pós-coloniais, tanto dentro da filosofia quanto da antropologia - e como ela possibilita a ampliação do estudo das dinâmicas políticas desde a pluralidade de sujeitos sociais contemporâneos, dentro dos quais encontram-se as comunidades religiosas. Como caso específico de estudo se tomará uma comunidade neopentecostal em Buenos Aires, o Centro Cristiano Nueva Vida (CCNV), onde analisaremos como dita igreja constrói sua identidade sócio-política desde os processos que se gestam desde sua especificidade religiosa, ou seja, seus discursos teológicos, processos simbólicos, ritos e modalidades institucionais.
\end{abstract}

Palavras chave: Identidade, pentecostalismo, sujeito, politica, religião. 
El concepto de identidad como categoría analítica ha tomado un lugar cada vez más importante dentro de los estudios sociales (Hall y du Gay, 2011). Ello responde, principalmente, a la crítica del sujeto moderno tan presente en las ciencias humanas, que se caracteriza por ver a los actores (individuales y colectivos) desde una visión suturada y homogeneizante tanto de su condición ontológica como de sus prácticas. En otros términos, la constitución de los sujetos sociales se describe de forma esencialista y como resultante de la sobredeterminación de caracterizaciones naturalizadas que forman parte de las estructuras determinadas en el contexto en que interactúan. Esto resulta en una serie de preconceptos analíticos que han tenido (y aún tienen) mucha fuerza en los análisis socioantropológicos vigentes: la comprensión de los agentes como emanaciones de una serie de elementos constitutivos inamovibles, la visión del campo social como un cúmulo de grupos definidos desde fronteras fijas y la descripción de las dinámicas del medio desde la presencia de movimientos estructurados a priori en búsqueda de un orden establecido. ${ }^{1}$

Estos marcos analíticos también intervienen en el estudio de los fenómenos religiosos, especialmente en la comprensión de las dinámicas internas y externas de sus comunidades. Podemos identificar diversas consecuencias. Por un lado, considerar las comunidades eclesiales como espacios homogéneos, cuyas dinámicas se encuentran lejos de los procesos sociales, lo cual resulta en la definición de un campo compuesto de particularidades circunscriptas en sí mismas y, de cierta forma, aisladas. Por otro, también puede llevar a comprender lo religioso solo como un efecto resultante de los mecanismos sociales, sea como respuesta o paliativo, sin considerar su particularidad constitutiva.

\footnotetext{
1 Desde una perspectiva crítica, esto no significa que la noción de sujeto esté deslindada de las dinámicas contextuales. Todo lo contrario. Lo que queremos resaltar es el hecho de que una visión estructuralista y suturada de las relaciones sociales conlleva un concepto de sujeto con las mismas características. Lo que las teorías postestructuralistas proponen - como veremos más adelante- es una complejización del análisis del campo sociocultural, lo que resulta en y de una concepción menos esencialista del sujeto. Véase Starvakakis (2007, pp. 69-110).
} 
De aquí que encontremos estudios que plantean la necesidad del uso de la categoría identidad en el análisis del campo como camino para superar estos reduccionismos (Algranti, 2009; Parker, 2012). Teniendo en cuenta lo dicho, debemos considerar que los avatares que se gestan a partir de los marcos epistemológicos que se utilizan tienen directa influencia en la identificación de los procesos que emergen de la relación entre lo religioso y el campo social, así como de los procesos dentro de los grupos, especialmente en lo que refiere a los mecanismos de autodefinición.

La noción de identidad, tal como lo han desarrollado diversos abordajes — dentro de corrientes de teoría política postestructuralista o antropología poscolonial, como desarrollaremos más adelante-, permite complejizar estos elementos, evidenciando tanto las tensiones inherentes a estas dinámicas — interna y externamente a los gruposcomo los procesos de relación que se crean con el contexto. En otros términos, se analizan las construcciones identitarias particulares como espacios de doble vía, donde se gestan múltiples procesos y tensiones entre una diversidad de elementos tanto internos como externos. En este sentido, ni lo identitario ni lo contextual son nomenclaturas homogéneas y determinadas a priori, sino construcciones discursivas, simbólicas, rituales y sociales en constante proceso de redefinición.

En este trabajo profundizamos brevemente en la noción de identidad como categoría analítica en esta dirección, especialmente desde el aporte de algunas teorías contemporáneas que ahondan en dichos temas. En este sentido, tratamos de ver cómo la antropología, en cuanto disciplina, realiza un aporte particular al respecto, especialmente en su análisis de las dinámicas que emergen en un espacio local/particular. Este análisis responde a tres ejes: el resurgimiento de la noción de identidad en la teoría social, la particularidad de la dimensión política del concepto y su aplicación al campo religioso. Culminamos con un estudio de caso, específicamente del Centro Cristiano Nueva Vida (CCNV) en Capital Federal de Argentina, cuyo análisis nos permitirá respaldar algunas de las categorizaciones introducidas. 


\section{Lo identitario como categoría analítica}

La resignificación de la noción de identidad puede ubicarse en un campo multifacético de causas: la crisis del paradigma moderno, las limitaciones de las teorías estructuralistas, el cuestionamiento a la cosmovisión occidental presente en la teoría social, el desarrollo de los estudios culturales, el surgimiento de las antropologías del Tercer Mundo, entre otros aspectos. A esto responde la emergencia de nuevos marcos epistemológicos, como las teorías postestructuralistas (en sus diversas variantes y disciplinas), la teoría del discurso, la deconstrucción derrideana, la influencia del psicoanálisis lacaniano y el lugar que van cobrando algunas propuestas "pos" (posmodernas, poscoloniales, etc.).

Podríamos mencionar varios aspectos respecto a este viraje. Uno de los elementos más significativos es la identificación de lo que muchos autores denominan diferencia constitutiva de toda identidad, lo cual implica dos puntos centrales: primero, que toda composición identitaria se constituye desde una heterogeneidad de elementos, los cuales no se encuentran en armonía, sino en una constante tensión que dinamiza su composición ontológica. Segundo, resalta la realidad de una exterioridad constitutiva (Derrida, 2002; Starvakakis, 2007; Laclau, 2000), donde los procesos sociales se ven siempre movilizados por un elemento fuera de sí que desafía la estabilidad de su estatus.

Aquí el concepto de alteridad, como noción que enmarca el conjunto de discursos, sujetos e instituciones, no solo va más allá de lo "propio" de la identidad particular, sino que también la atraviesan, deconstruyendo y desestabilizando sus fronteras demarcatorias (Segato, 1999). A su vez, implica un movimiento de reposicionamiento constante de las identidades mediante procesos de identificación con los diversos elementos que componen su contexto (Guattari y Rolnik, 2005; Hall, 1990; Laclau y Mouffe, 1987). Esto, a su vez, parte de la premisa de que toda identidad responde a una constitución discursiva, lo que ubica su locus en una instancia hermenéutica, desde los complejos juegos de sentido e interpretación. 
De aquí que toda identidad es inherentemente contingente (Laclau, 2000). Esto significa que ella no representa un estatus de sutura y homogeneidad, sino que se ve constantemente "amenazada" por los procesos de transformación que parten de la interacción inscrita en su heterogeneidad constitutiva, así también por lo otro externo a ella. Esto es, las identidades son segmentaciones parcialmente delimitadas, pero no completamente clausuradas, que se encuentran en constante proceso de redefinición según los complejos procesos de construcción que las atraviesan. Es lo que Laclau (2000) denomina procesos de dislocación.

De aquí, por último, la importancia del sentido de pluralidad/pluralización como dinámica respectivamente constitutiva/disruptiva de lo identitario. Estas nociones son centrales para describir no solo su composición heterogénea hacia sí misma, sino también hacia fuera, dentro del contexto en que se inscriben. En otras palabras, lo identitario se constituye irremediablemente en un espacio plural, cuyas fronteras no se encuentran delimitadas, sino fisuradas desde las tensiones emergentes que parten de las interacciones en que se circunscriben.

Como ya mencionamos, esta definición de identidad deviene también una comprensión particular de lo contextual en cuanto espacio plural y con delimitaciones porosas. Esto es importante considerar, ya que el énfasis en lo identitario, centrado en el lugar o acción del actor/agente/sujeto concreto, puede caer en el mismo peligro de la absolutización y esencialismo cuestionado al inicio. Por ello es central evidenciar que estas dinámicas de pluralización y dislocación se gestan no solo por la intervención directa de los sujetos particulares, sino por las interacciones que emergen desde los intersticios inherentes a las fronteras - o los espacios entre-medio, como diría Homi Bhabha (2002) - , que circunscriben y fisuran el espacio sociocultural de la constitución de discursos identitarios.

De aquí, por ende, la importancia de vincular identidad y cultura, entendiendo esta última como un espacio simbólico desde donde se construye el sentido del locus de los sujetos, sus interacciones y sus contextos (Geertz, 2006, pp. 43-59). Aquí un elemento importante, 
que suele ser un cuestionamiento a las teorías de la identidad: este abordaje no deja de lado el contexto o un análisis macro, sino, por el contrario, localiza sus dinámicas. Más aún, evidencia la complejidad de sus operaciones, al deconstruir las fronteras que lo delimitan, y con ello los mecanismos de socialización, institucionalización y discurso inherentes a él.

\section{Lo político de la identidad}

El concepto de identidad ha sido recuperado como categoría de análisis politico, especialmente en lo que refiere a las reconfiguraciones del campo en cuanto a la pluralización de sujetos y modos de institucionalización política. La diferenciación entre lo político como dimensión agonística constituyente de todo grupo social desde los procesos de construcción de sentido y la política como conjunto de procesos de segmentación que historizan pasajeramente dicha dinámica a través de procesos de institucionalización (Mouffe, 2007, p. 16) ha abierto una instancia de crítica a la absolutización de ciertos actores y nociones sociales tradicionales, como Estado, partido, ideología, nación/ nacionalismo, etc., que permiten la evidenciación de una pluralización de discursos, de símbolos y de estructuraciones institucionales que pueden reflejarse en diversas particularidades, como movimientos sociales, organizaciones, discursos vinculados a minorías étnicas o sexuales, iglesias y comunidades religiosas, entre muchas otras.

En este contexto, hay tres términos que asumen una relevante importancia: pluralismo, conflicto y articulación. Sobre el primer término ya nos hemos referido, aunque aquí cobra un nuevo significado: lo político se vincula directamente con la creación de un espacio plural y heterogéneo de acción e interpretación. En este sentido, lo político no se relaciona únicamente con la burocracia o administración institucional, sino con la necesidad de constituir instancias que promuevan la heterogeneidad de lo social, sus expresiones y sus modos de construcción de sentido (Santos, 2006). En otras palabras, la pluralización de lo identitario posee en sí misma una dimensión política, en el sentido de habilitar una hetrogeinización de los modos de significación. 
La idea de conflicto (Rancière, 2010) implica reconocer las tensiones inherentes a los procesos de construcción de lo político, teniendo en cuenta las dinámicas de pluralización de lo identitario y las interacciones que se producen entre ellas, con el propósito de responder a diversos elementos constitutivos de lo social: la atención a demandas populares (Laclau, 2005), los conflictos de sentido que se gestan en los procesos de interpretación de la realidad (o sea, la disputa por los sentidos de verdad) y el control de las dinámicas de poder.

Por último, las interacciones conflictivas que se dan entre los elementos de esta pluralidad inherente al campo social conllevan una práctica de articulación entre las diversas partes, elemento que profundiza la construcción plural de lo identitario y, más aún, sus prácticas. Una relectura de la idea gramsciana de hegemonía toma lugar aquí, donde se comprende la construcción de lo identitario — remitiendo a Foucault (2002) — desde una lógica equivalencial de discursos, experiencias y prácticas que alcanzan demarcaciones relativamente estables para responder a los elementos mencionados, pero cuya condición heterogénea imprime la suficiente inestabilidad para mantenerla en un proceso constante de redefinición en la medida en que dichas demandas cambian (cfr. concepto de populismo en Laclau, 2005).

\section{Lo identitario y la antropología}

Teniendo en cuenta lo dicho hasta aquí, el análisis de lo político — desde la perspectiva de la construcción de identidades — se amplía y proyecta hacia el estudio de los universos de sentido que encauzan las dinámicas socioculturales - lo cual remite al lugar de lo simbólico, discursivo y ritual—, una visión plural de los actores sociales y sus reivindicaciones identitarias, las complejidades de los juegos de poder desde un enmarque micro (lo cual responde a un estudio localizado de las dinámicas sociopolíticas), entre otros elementos.

Por ello creemos que la antropología politica, en cuanto subdisciplina, ofrece un marco de análisis propicio para el análisis de estos elementos (Aronoff y Kubik, 2012; Swartz, Turner y Tuden, 1994; Abélès, 1997 
y 2008; Balandier, 2004). Los diversos estudios sobre el concepto de cultura política permiten ampliar el campo de análisis hacia la diversidad de prácticas significantes de las acciones y sentidos sociales, así como los diversos actores y dinámicas institucionales que entran en juego, los cuales van más allá de los procesos de burocracia y administración estatal o partidaria (Landi, 1988; Calles Santillana, 1999; De la Roche, 2000). También encontramos análisis de los procesos simbólicos en las dinámicas de poder y las disputas microsociales por su construcción (Geertz, 2006; Gledhill, 2000).

En este sentido, uno de los elementos en los cuales la antropología ha hecho hincapié es en la noción de práctica como marco de constitución del sujeto y su identidad, ubicando su estatus ontológico no como una constitución fija, sino como una construcción desde la heterogeneidad de estos procesos por medio de la diversidad de posicionamientos que va adquiriendo dentro del entramado sociocultural, lo cual cuestiona toda esencialización de su locus (Isla, 2009). Esto, a su vez, posee una intrínseca importancia política, ya que posiciona la acción del sujeto concreto en un marco positivo de acción, reacción, resistencia y subversión en torno a los marcos de identificación preestablecidos (Comaroff y Comaroff, 1991; Scott, 1985). En palabras de Esteban Krotz (1997), la antropología provee un análisis de la orientación subjetiva hacia la política, enfocándose en la perspectiva del actor.

En resumen, los nuevos abordajes de la noción de identidad sirven a la complejización del análisis social —en especial de sus dinámicas políticas, tal como hemos hecho hincapié en este trabajo- poniendo el relieve en el estudio de las interacciones (lo relacional), las interpretaciones (el sentido y lo hermenéutico), la alteridad (la heterogeneidad) y las tensiones (lo conflictivo) que definen la maleabilidad de la construcción de lo social. Como ya hemos dicho, esto supera las discusiones entre lo micro y lo macro, lo local y lo global, lo particular y lo plural como extremos enfrentados, ya que los inscribe en un proceso de interacción e interpenetración, que reivindica la polivalencia de las construcciones según su segmentación particular. 


\section{Pentecostalismo e identidad política: el caso del Centro Cristiano Nueva Vida}

Tal como hemos mencionado, la noción de identidad también implicó cambios en el análisis del fenómeno religioso, y con ello en el estudio del pentecostalismo: el tema que aquí nos interesa indagar. Joaquín Algranti (2009) — remitiendo a María Julia Carozzi- habla del giro antropológico en el estudio de lo religioso, y con ello de la utilización específica de la noción de identidad, que deja de lado los reduccionismos estructuralistas y revaloriza el análisis de la especificidad religiosa a partir del estudio de las interacciones de los actores. Por su parte, Parker (2012, p. 31) — quien parte su análisis desde la evidenciación de la pluralización de los sujetos políticos en América Latina- afirma que las identidades religiosas se construyen desde premisas simbólicoculturales y no ideológicas, lo cual ofrece una lectura particular de sus modalidades políticas.

Uno de los analistas que más han utilizado la noción de identidad para el estudio de lo religioso en relación con las dinámicas políticas ha sido Joanlido Burity (2008 y 2009), quien toma de los aportes del postestructuralismo - especialmente en Ernesto Laclau y Chantal Mouffe — para analizar las dinámicas internas y externas —o lo que denomina dimensión colectiva (la relación de lo religioso con movimientos sociales y políticos) y dimensión diseminativa (las modificaciones de lo religioso en las trayectorias políticas personales) — de las comunidades evangélicas en el Cono Sur, especialmente en Brasil y Argentina. Burity no solo analiza los procesos particulares de redefinición de nociones políticas dentro de las comunidades religiosas — teniendo en cuenta la especificidad de los códigos teológicos a los cuales responden-, sino que evidencia la transformación existente en la pluralización de instancias de trabajo conjunto entre religiones y Estado, así como el reconocimiento de lo religioso como una expresión más dentro del creciente espectro de organizaciones, movimientos sociales e institucionalizaciones alternativas de lo político.

Para profundizar en este abordaje, tomamos el caso particular del CCNV, una comunidad neopentecostal que surge en 1982 y que ha ex- 
perimentado un crecimiento exponencial, al transformarse en una de las megaiglesias más influyentes de Argentina. En su historia como comunidad eclesial ha experimentado diversos procesos que han determinado de manera particular tanto su comprensión de sí misma como su funcionamiento estructural y contextual (Panotto, 2013); pero un estudio de su trayectoria como iglesia pone en evidencia de qué manera una coyuntura social particular — la crisis de 2001 en Argentina - transformó profundamente la práctica y el discurso de esta iglesia, sobre todo lo que refiere a su acción sociopolítica.

$\mathrm{Al}$ retomar los elementos desarrollados hasta aquí, nos concentraremos en analizar cómo se construye la identidad del CCNV y en qué medida los aspectos característicos de dicha noción dinamizan los procesos sociopolíticos en los cuales la iglesia se ve inmersa. Para ello, retomaremos tres categorizaciones ya desarrolladas en el texto, que nos servirán como guía para este análisis: las dimensiones de diferenciación constitutivas (la heterogeneidad de elementos internos y externos que entran en juego en la composición de la identidad del grupo y las dinámicas que ello produce), los esquemas autorreferenciales de la cosmovisión sociopolítica (cómo la comunidad eclesial se ubica a sí misma, desde su particularidad religiosa, dentro de la arena pública) y las instancias de articulación institucional (las formas de vinculación con otros agentes sociales y los discursos y prácticas particulares desde el espectro religioso que lo posibilitan). Utilizamos como recurso la información sustraída de entrevistas a parte del liderazgo, observación participante y análisis de textos producidos por el pastor principal, Guillermo Prein.

\section{Las diferencias constitutivas}

Respecto a las dimensiones de diferenciación, afirmamos que toda identidad, lejos de ser un cuadro homogéneo y delimitado, se encuentra atravesada por una diferencia constitutiva, que responde tanto a la pluralidad de elementos que la compone como a una exterioridad que la desafía. Más aún, ella se establece en la comprensión de sí misma como "diferente a" un otro. En el caso del CCNV podemos encontrar varios elementos que representan esta diferencialidad constitutiva que, en muchos aspectos, responde a los imaginarios evangélicos, en 
general, y a los pentecostales, en particular. Para nuestro estudio, trabajamos especialmente tres instancias que aparecen en el discurso del CCNV en diversos niveles: las distinciones con respecto a otros grupos religiosos, el concepto teológico de reino de Dios y las cosmovisiones demonológicas.

La diferenciación con otros grupos religiosos se relaciona en especial con una crítica a sectores de las iglesias católica y evangélica. En los últimos años, el pastor principal del CCNV, Guillermo Prein, ha encabezado una serie de fuertes cuestionamientos hacia la institución católica. Ello lo podemos ver, por ejemplo, en su crítica al proyecto de ley sobre libertad religiosa presentado por la entonces "diputada evangélica" Cynthia Hotton. Junto a un grupo de abogados, analiza con detalle la propuesta y afirma que esta no hace más que reafirmar el privilegio de la Iglesia católica y poner en el mismo rango las instituciones evangélicas y violar con ello el derecho a la diversidad religiosa (Prein, 2010). Por otro lado, las discusiones en torno a la reforma del Código Civil durante 2012 llevaron a Prein a publicar una serie de escritos que criticaban el lugar preferencial del catolicismo y la necesidad de una reforma para igualar los derechos de participación y reconocimiento (Prein, 2012). También participó de las sesiones de consulta en la Comisión Bicameral del Congreso de la Nación sobre el anteproyecto de Reforma del Código Civil y Comercial (4 de septiembre de 2012). Prein, además, ha denunciado públicamente, a través de predicaciones dominicales en su iglesia, la connivencia entre el ministro de Educación del Gobierno de la Ciudad y la Iglesia católica, especialmente en lo vinculado con los beneficios presupuestarios otorgados a esta última.

Se encuentra muy presente también en el discurso general del CCNV, tanto de parte del liderazgo como de los miembros en general, un cuestionamiento a la iglesia evangélica. En este sentido, es interesante notar que, más allá que el CCNV sea una comunidad neopentecostal, mantiene fuertes tensiones con los sectores evangélicos tradicionales, sobre todo con los grupos vinculados a la Alianza Cristiana de Iglesias Evangélicas de la República Argentina (Aciera). En varias entrevistas surgieron fuertes observaciones contra esta federación de iglesias, la 
cual es vista como una expresión conservadora y "neoliberal", tanto desde lo teológico como desde lo político.

Uno de los puntos principales de conflicto fue el apoyo que el CCNV otorgó a la promulgación de la Ley de Matrimonio Igualitario, lo cual le costó críticas por parte del sector evangélico vinculado a Aciera; pero principalmente podemos ver que "la iglesia evangélica" emerge dentro del discurso en el CCNV desde un intento de diferenciación con ciertos elementos vinculados, por ejemplo, a la falta de influencia social, a su discurso apolítico, a la cosmovisión conservadora (social y eclesiológica), entre otros elementos, que representa ese espectro eclesial. Dicha diferenciación sirve, por ende, a la afirmación de una identidad propia que responde a parámetros identitarios particulares: la necesidad de mayor influencia en el campo social, la importancia de promover la militancia política, el desafío de crear una estructura eclesial inclusiva, entre otros aspectos (Contins, 2008).

Los próximos dos elementos que analizamos están más bien vinculados a la cosmovisión teológica del CCNV, los cuales — aplicando una lectura antropológica - se relacionan con dinámicas simbólicas, discursivas y rituales particulares de la comunidad, en relación con su inscripción en el contexto sociocultural. Por una parte, encontramos el concepto de reino de Dios, el cual es uno de los más importantes dentro de la tradición cristiana. Este remite a la escatología bíblica y se encuentra presente tanto en el Antiguo Testamento como en el Nuevo Testamento. Apela a una acción futura de Dios en la historia, sea para liberar al pueblo de Israel o para juzgar a la humanidad. Las lecturas contextuales que emergieron a partir de la década de los setenta, especialmente desde la teología de la liberación en América Latina, trabajan este concepto desde un estudio de la vida histórica de Jesús, sobre todo en su labor con los pobres y su denuncia a los poderes religiosos y políticos. Aunque esta tradición específica no influyó considerablemente en la iglesia pentecostal, sí lo hizo cierta lectura matizada que afirma que el reino de Dios no es solo una realidad futura, sino una condición que comienza a gestarse en el presente a través de la acción de los creyentes en la sociedad. 
Esta última cosmovisión es muy evidente dentro del CCNV. Vemos, por ejemplo, que Guillermo Prein (2008) afirma lo siguiente en una reflexión bíblica respecto a este tema:

Un texto clave para entender tu tiempo y tu identidad es Lucas 10: Obedecer al Maestro, evangelizar, recibir provisión divina, la manifestación de milagros y poder de Dios, el diablo derrotado y nosotros gozándonos porque nuestros nombres figuran en el libro de la vida. Viviremos con Él por la eternidad la que, dicho sea de paso, comienza en esta tierra y por eso nos enseñó a orar diciendo: "Venga a nosotros tu reino".

Más aún, la noción de reino de Dios posee una fuerte implicancia política, pero no en el sentido partidario, sino militante. En una entrevista realizada también a Prein (Barragán Elia, 2010), a la pregunta “¿Por qué a la iglesia evangélica le cuesta más introducirse en la política?”, este responde:

Porque no entiende que significa "Mi reino no es de este mundo". Unos creen que es alejarse de todo lo "mundano". Los otros que creen estar superados, entran en la política de la misma manera que los políticos la desarrollan. Es vergonzoso. Tenemos una cultura diferente, la Cultura de Jesús y debemos esparcirla en todo ámbito en el que nos desarrollemos [...] Muchos quieren hacer política con los políticos y llegar a lugares encumbrados, y para ello usan a la Iglesia. Otros creemos que tenemos que andar con la gente defendiéndoles y preocupándonos por ellos. Gente y no cargos [...] En definitiva, la Iglesia no debe introducirse en la política, debemos estar al lado de la gente con todo lo que esto implica, atendiendo las necesidades de la gente, ya que esto es la prioridad uno para Dios y así debe ser para nosotros [...] Hablar menos, escuchar más y darnos por completo.

El concepto de reino de Dios se relaciona con una tensión inherente a la identidad cristiana: por un lado, responde a una realidad que se espera "más allá" (tanto histórica como teológicamente); por otro, se vincula estrechamente con los avatares y dinámicas históricas de la 
cotidianeidad de los creyentes. Las dos menciones de Prein nos permiten ver que el reino de Dios tiene directa relación con el contexto social y su transformación y que representa una condición disruptiva por parte de la acción de la iglesia, que va más allá de las formas de institucionalidad y mecanismos de intervención social. Esto se relaciona con lo que Hilario Wynarczyk (2009) denomina como el paso de un dualismo negativo a un dualismo positivo: mientras el primero apartaba a la iglesia del "mundo", el segundo pone a la primera como prototipo moral y ético del segundo.

En resumen, la idea de reino de Dios como una realidad paradójica cuya condición es suprahistórica y, a su vez, inserta en la realidad, hace que la comunidad eclesial se comprenda a sí misma en la frontera de una tensión entre una vivencia histórica concreta y la influencia en el contexto, siempre emergente en la experiencia de la espiritualidad. En otros términos, la tensión que efectiviza la presencia del reino promueve una visión dinámica de lo social, la cual siempre se encuentra abierta a la intervención de lo divino, en especial de la mano de la comunidad creyente.

Por último, el CCNV también responde a una cosmovisión particular sobre la acción del diablo y la intervención de los demonios, también llamada guerra espiritual (Algranti, 2010, pp. 191-199). Esta teología responde a una visión que sostiene que "detrás" de la realidad histórica concreta intervienen fuerzas del bien (Dios) y del mal (Diablo), que van condicionando de diversas maneras los avatares cotidianos que se presentan. La Iglesia y los creyentes poseen una sensibilidad particular sobre dicha disputa, lo que los ubica en un lugar de cierta negociación, lucha e intervención. Más aún, lo demoniaco se relaciona con los sufrimientos que atraviesan las realidades específicas y diarias.

Lo que puede parecer un imaginario mágico de la realidad - $-\mathrm{y}$, por ende, deshistorizado - cobra otros matices al partir la lectura desde el dualismo positivo que acabamos de describir. En este sentido, es interesante notar que en los momentos de reprensión dentro de los cultos eclesiales se nominan las fuerzas demoniacas desde problemáticas cotidianas de los creyentes: espíritu de depresión, de culpa, de 
desánimo, de tristeza, entre otros. En una predicación de Prein, este afirma que "el diablo conoce nuestro idioma y nos habla en nuestro idioma", haciendo hincapié en el hecho de que ciertas acciones que las personas realizan no parten de ellas, sino del Diablo que hace pensar lo contrario. En esta misma predicación, Prein afirma que existen demonios detrás de los economistas del país, quienes constantemente promueven teorías falsas para desanimar el espíritu social. “¡Esos son los espíritus que debemos reprender!”, sentencia. Esto refleja cómo las fuerzas demoniacas se relacionan directamente con los avatares no solo cotidianos, sino también sociopolíticos.

En la misma dirección de lo tratado en el punto anterior sobre el reino de Dios, la realidad demoniaca imprime una cosmovisión conflictiva de lo social y, por ende, dinámica. El contexto se encuentra en un proceso constante de transformación en la medida de que esta "batalla" se desarrolle. Pero ella tiene como epicentro la misma vivencia de los creyentes en el contexto social, por lo cual hay un llamado a la intervención de los sujetos. Como afirma Cantón (2009), esta cosmovisión implica una dimensión práctica cuya apelación al "alejamiento del mundo" no lleva en sí una apatía sobre la realidad, sino un distanciamiento de ciertos elementos sociales que provocan sufrimiento, para desde allí intervenir en la fuerza espiritual del bien.

\section{Sujetos-creyentes y hermenéuticas teológico-políticas}

Respecto a los esquemas autorreferenciales, nos referimos específicamente a cómo el CCNV define su identidad en términos sociopolíticos. Lo que queremos resaltar, en línea con lo que venimos afirmando, es la pluralidad constitutiva de la identidad del CCNV. Ello lo podemos atribuir, principalmente, a factores eclesiológicos y teológicos. En primer lugar, hay un elemento constitutivo de las iglesias evangélicas, que es la interpretación personal del texto bíblico sin mediación externa al creyente. En este sentido, los sujetos creyentes se transforman en sujetos hermenéuticos que construyen el sentido del texto bíblico a la luz de sus experiencias y contextos, los cuales son, a su vez, resignificados a partir de dichos marcos de sentido (Panotto, 2013). Más aún, los encuentros de reflexión bíblica a los que asisten la mayoría de los participantes 
del CCNV (denominados espigas, las cuales se convocan mayormente en casas de familia) se transforman en espacios de diálogo y reflexión sobre las diversas interpretaciones de la Biblia desde las experiencias concretas de los participantes. Estos elementos se radicalizan aún más dentro de la cosmovisión neopentecostal, la cual promueve con más fuerza que otras expresiones evangélicas la importancia de la experiencia espiritual individual y de los testimonios personales como relatos que sirven de marco hermenéutico para estas lecturas.

En este sentido, el texto bíblico se transforma en un campo narrativo que resignifica experiencias y sentidos sociales y políticos. Esto es muy común en varios de los escritos de Guillermo Prein, quien fusiona léxicos y pasajes bíblicos con relatos y situaciones cotidianas. Por ejemplo, hablando de las dinámicas económicas de Argentina en la última década, Prein (2013) escribe lo siguiente:

Sudando con el pueblo, olimos a ovejas empapadas en desesperación. A puro milagro salimos adelante, como guerreros contra la muerte. Con saladas lágrimas de dolor y alegría [...] sazonamos nuestra Patria herida [...] Diez años de cosechas magníficas y precios internacionales extraordinarios levantaron al país de su peor tumba, pero a su vez, activaron la levadura de mezquinos expertos en artimañas. Aquel silencio fue destrozado por sobrinos impertinentes $[\ldots]$ todos hablaban $[. .$.$] hablan y hablan. Parecido$ a las parábolas bíblicas [...] Moab, sodomita, siempre oprime a quienes migran en su debilidad; $y$, aun cuando la verdad yuxtaponga sentimientos en nuestra alma, tenemos que tirar al mar a todos los jonases [...] para que mediten en la solitaria y húmeda barriga de la ballena y de esa forma cambien, si es que quieren formar parte de la Patria, que viva se desarrolla y toma forma cada día.

El CCNV ubica en un lugar central la acción e intervención de los creyentes, no solo como intérpretes del texto bíblico, sino como actores centrales de la vida de la Iglesia. Claudio, un miembro del CCNV — también vinculado en actividades políticas_-, dice lo siguiente: "Lo que a mí me habla es que cada uno que tenga una intencionalidad hacia un 
área, le dan ahí... Y eso habla de que cada visión, cada ocasión, cada deseo, cada llamado, se puede canalizar".

Por otro lado, uno de los miembros del cuerpo pastoral del CCNV también afirma lo siguiente:

Todo el mundo, cada uno es importante. Y cada uno desarrolla en la amplitud de lo que puede desarrollar... Cada uno no tiene un límite sobre cómo desarrollarse, de poder participar. Porque la gente, todo el mundo que está interesado, puede participar, cosa que vos en muchos otros sectores no podés participar... Totalmente, libremente.

Estos relatos evidencian dos elementos centrales respecto a la definición identitaria del CCNV: la importancia del sujeto creyente como agente activo y la comprensión heterogénea de lo eclesial. Esto deriva en la importancia de la pluralidad constitutiva del CCNV, que se comprende a sí mismo como un actor social compuesto por unos individuos, quienes a su vez representan cosmovisiones y discursos en tensión. Por ejemplo, una de las áreas más importantes del CCNV, que trabaja directamente en incidencia política, es Liberando Argentina con Trabajo y Educación (LATE). Dicho grupo se compone de hombres y mujeres tanto de la misma comunidad eclesial como de personas del barrio que realizan trabajos de incidencia social, en conjunto también con otros organismos. El coordinador de este proyecto describe el grupo de la siguiente manera:

LATE es un espacio plural, políticamente hablando. Y es lo que más defiendo; defiendo con todo eso. Porque para nosotros es muy importante que dentro de LATE pueda convivir alguien de Frente para la Victoria, alguien de Proyecto Sur, alguien del PRO, alguien de lo que se le cante, porque que en definitiva nos une un proyecto que sea para el bien común.

En un encuentro de LATE con otras áreas del CCNV — que congregó a más de doscientas personas-, donde se planificaron una serie de actividades de incidencia sociopolítica en conjunto, Guillermo Prein 
llevó a cabo una reflexión final en la cual instaba a que la Iglesia, y especialmente el grupo presente, debía considerarse a sí mismo un movimiento. Las características que esbozó fueron las siguientes: se reciben a distintas personas unidas por una causa, se aceptan todos los espectros políticos ("sean del PRO o K") y se debe configurar como una asamblea ("no para que todos digan 'sí, sino para dialogar"). Remarcó que la participación no está condicionada a ser evangélicos. "A veces me llevo mejor con los ateos que con los religiosos", afirmó. Por último, invita a expresar lo que se siente, a reconocer los errores y, sobre todo, a que "sean flexibles como todo movimiento necesita flexibilidad. No podemos ponernos rígidos”.

A través de estos ejemplos podemos ver que el sentido de pluralidad y de acción por parte de los sujetos concretos tiene un lugar central en el CCNV, no solo como un elemento coyuntural, sino como parte de una cosmovisión sociopolítica. Lo que vale resaltar en este sentido es que dicha cosmovisión no deviene solamente de un enmarque filosófico o ideológico estrictamente "político"; principalmente desde las caracterizaciones distintivas de la construcción de lo eclesial, los discursos teológicos y de las prácticas religiosas. En otros términos, la reivindicación del sujeto creyente como constructor de sentido o como actor central dentro de la institución —elementos representativos de la cosmovisión evangélica y pentecostal— son instancias que, desde su especificidad, permiten construir una identidad en el sentido sociopolítico (López, 2000).

\section{Articulación y acción sociopolítica}

Por último, mencionamos el lugar de las instancias de articulación. Este elemento ya lo hemos trabajado con detalle en otro escrito (Panotto, 2013), por lo cual no nos ocuparemos en profundidad de ello. Nos referiremos específicamente a los espacios de trabajo conjunto con diversas organizaciones y espacios de incidencia pública. En el caso específico del CCNV, existen varios ejemplos de articulación. LATE, por su parte, ha participado de diversas instancias de diálogo con agrupaciones políticas para debatir sobre la situación social y política de la ciudad. El CCNV también cuenta con un establecimiento de carreras 
terciarias — el Centro de Estudios Nueva Vida (CENV) — al cual asisten más de quinientos estudiantes. Dicha institución posee convenios con el Ministerio de Trabajo, el Ministerio de Educación y el Ministerio de Salud, para la acreditación de carreras y apoyo a diversos proyectos sociales. Respecto a esto último, vale resaltar la experiencia con el Programa Nacional de Alfabetización que el CCNV está desarrollando desde las diversas comunidades que lo componen, con más de cincuenta alfabetizadores que utilizan los templos de reunión para desarrollar dicho programa.

Según lo ya dicho, lo que importa resaltar en cuanto a este punto es que dichas dinámicas de articulación se relacionan directamente con la cosmovisión sociopolítica de la comunidad eclesial, como espacio religioso. En este sentido, la iglesia se transforma en un campo de acceso a recursos simbólicos, humanos e institucionales que para los miembros de la comunidad sería imposible disponer desde otra instancia. Más aún, estos procesos de articulación definen la identidad propia de la iglesia en dos sentidos. En primer lugar, hacen del locus eclesial un espacio heterogéneo, donde entran en juego diversos agentes que —incluso_ - van más allá de las caracterizaciones eclesiales evangélicas (como son partidos políticos, ministerios nacionales, organizaciones no gubernamentales, etc.). En segundo lugar, estas dinámicas — junto con otras instituciones, discursos y personas - constituyen un espacio de encuentro con alteridades que dislocan prácticas, institucionalidades y discursos, que deconstruyen constantemente el estatus ontológico del CCNV, al tener que responder de diversas maneras a dicha pluralidad, creando proyectos de trabajo fuera de la ortodoxia pentecostal y revisando discursos teológicos, instancias litúrgicas, etc.

\section{Conclusiones}

En este trabajo hemos propuesto una relectura de la relación entre religión, pentecostalismo y dinámicas sociopolíticas desde los nuevos abordajes vigentes sobre el concepto de identidad (especialmente identidad cultural y política). Dicho análisis nos ha permitido profundizar en las complejas relaciones que se gestan tanto interna como externamente a la comunidad eclesial, especialmente en lo referido a 
la construcción de sentidos políticos y acciones sociales en el espacio público. En este sentido, los nuevos abordajes en torno a lo identitario permiten desarrollar más en profundidad las tensiones e interacciones entre lo micro y lo macro, lo particular y lo plural, indagando en los procesos que se gestan entre las fronteras de dichas demarcaciones, lo cual implica una comprensión dinámica tanto del contexto como de la constitución ontológica de lo identitario.

Ello permite redefinir el estatus político de lo identitario desde una comprensión más amplia, o sea, desde la construcción de sentidos hermenéuticos e interpretativos, desde la centralidad que cobra la promoción de un campo plural de identificaciones y desde las dinámicas de articulación tanto internas como externas al grupo, que complejizan la autodefinición de lo identitario y su intervención en el campo social. En otras palabras, el sentido de lo político se proyecta más allá de nociones como burocracia, gestión o ideología, hacia un campo más amplio, donde se evidencia la intervención de una pluralidad de sujetos, discursos y narrativas. En esta localización de lo político, epistemológicamente, se considera la importancia de diversos elementos, como las dinámicas simbólicas, las discursivas y las rituales.

El estudio del CCNV nos ha permitido evidenciar cómo las nociones de autodefinición institucional, así como los recorridos personales de los creyentes respecto a lo sociopolítico, circulan desde dinámicas constitutivas a la iglesia, relacionadas con los procesos de diferenciación interna (sea en el campo de la interacción como en el ontológico), el reconocimiento de la pluralidad constitutiva de lo eclesial (y la necesidad de mantener abierta esa heterogeneidad como instancia de construcción política) y los procesos de articulación en los mecanismos de intervención social.

\section{Referencias}

Aronoff, M. y Kubik, J. (2012). Anthropology and political science: a convergent approach. Oxford: Berghahn Books.

Abélès, M. (1997). La antropología política: nuevos objetivos, nuevos objetos. Revista Internacional de Ciencias Sociales (153). Recuperado de http:// 
iidypca.homestead.com/FundamentosAntropologia/Abeles_-_La_ antropolog_a_pol_tica.pdf

Abélès, M. (2008). Politica de la supervivencia. Buenos Aires: Eudeba. Algranti, J. (2009). Auge, decadencia y 'espectralidad' del paradigma modernizador: viejos y nuevos problemas en el estudio del pentecostalismo en América Latina. En C. Steil, E. Martín y M. Camurca, Religiones y culturas: perspectivas latinoamericanas (pp. 57-87). Buenos Aires: Biblos.

Algranti, J. (2010). Política y religión en los márgenes. Buenos Aires: Ciccus.

Balandier, G. (2004). Antropología política. Buenos Aires: Del Sol.

Barragán Elia, D. (26 de abril, 2010). Guillermo Prein: “La Iglesia no entiende que significa 'Mi reino no es de este mundo"'. Boomker.com. Recuperado de http://www.boomker.com/guillermo-prein-la-iglesia-no-entiendeque-significa-mi-reino-no-es-de-este-mundo.

Bhabha, H. (2002). El lugar de la cultura. Buenos Aires: Manantial.

Burity, J. A. (2008). Religião, política e cultura. Tempo Social, 20 (2), 83-113.

Burity, J. A. (2009). Religião e lutas identitárias por cidadania e justiça: Brasil e Argentina. Ciências Sociais Unisinos, 45 (3), 183-195.

Calles Santillana, J. A. (1999). Recepción, cultura política y democracia. En Comunicación y sociedad (pp. 47-69). México: Universidad de Guadalajara.

Canclini, N. (2001). Culturas híbridas. Buenos Aires: Paidós.

Cantón, M. (2009). Simbólica y política del diablo pentecostal. Revista Cultura $y$ Religión, Chile, 81-94.

Comaroff, J. y Comaroff, J. (1991). Of revelation and revolution. London: The University of Chicago Press.

Contins, M. S. (enero-junio, 2008). Religião, Etnicidade e globalização: uma comparação entre grupos religiosos nos contextos brasileiro e norteamericano. Revista de Antropologia, 51 (1), 67-106.

De la Roche, F. (2000). Aproximaciones al concepto de cultura política. Convergencia. Revista de Ciencias Sociales, 7 (22), 93-123.

Derrida, J. (2002). De la gramatología. Madrid: Editora Nacional.

Hall, S. (1990). Cultural identity and diaspora. En J. Rutherford (Ed.), Identity: community, culture, difference (pp. 223-237). London: Lawrence \& Wishart.

Hall, S. y du Gay, P. (comps.), (2011). Cuestiones de identidad cultural. Buenos Aires: Amorrortu.

Foucault, M. (2002). La arqueología del saber. Buenos Aires: Siglo XXI.

Geertz, C. (2006). La interpretación de las culturas. Barcelona: Gedisa.

Gledhill, J. (2000). Elpodery sus disfraces. Barcelona: Balaterr. 
Guattari, F. y Rolnik, S. (2005). Micropolitica: cartografías del deseo. Buenos Aires: Tinta Limón.

Isla, A. (2009). Los usos politicos de la identidad: criollos, indígenas y Estado. Buenos Aires: Araucaria.

Krotz, E. (1997). La dimensión utópica en la cultura política: perspectivas antropológicas. En R. Winocur (coord.), Culturas políticas a fin de siglo. México: Flacso.

Laclau, E. (2000). Nuevas reflexiones sobre la revolución en nuestro tiempo. Buenos Aires: Nueva Visión.

Laclau, E. (2005). La razón populista. Buenos Aires: FCE.

Laclau, E. y Mouffe, C. (1987). Hegemonía y estrategia socialista. Buenos Aires: FCE.

Landi, O. (1988). Reconstrucciones: las nuevas formas de la cultura política. Buenos Aires: Puntosur.

López, D. (2000). Pentecostalismo y transformación social. Buenos Aires: Kairós. Mouffe, C. (2007). En torno a lo politico. Buenos Aires: FCE.

Panotto, N. (2013). Religión y nuevas formas de militancia: pentecostalismo y política en Capital Federal. Revista Proyecto, 24 (61-62), 203-221.

Parker, C. G. (2012). Religión, cultura y política en América Latina: nuevos enfoques. En C. G. Parker (Ed.), Religión, politica y cultura en América Latina: nuevas miradas (pp. 13-73). Santiago de Chile: Universidad de Santiago de Chile.

Prein, G. (26 de junio, 2008). El golpe. Recuperado de http:/ / guillermoprein. wordpress.com/2008/06/26/el-golpe/

Prein, G. (2010). Proyecto de Ley de Cultos. Recuperado de http:/ /www.ccnv. org/secciones/multimedia/ley_de_cultos/pdf/PROYECTOdeLEYdeCULTOS.pdf

Prein, G. (2012). Por una Patria de iguales. Recuperado de http:/ / www.guillermoprein.com/2012/09/por-una-patria-de-iguales.html

Prein, G. (2013). Se cumple hoy como ayer. Recuperado de http://www.guillermoprein.com/2013/04/se-cumple-hoy-como-ayer.html

Rancière, J. (2010). El desacuerdo. Buenos Aires: Nueva Visión.

Santos, B. de Sousa (2006). Reinventar la democracia, reinventar el Estado. Buenos Aires: Clacso.

Scott, J. (1985). Weapons of the weak. London: Yale University Press.

Segato, R. L. (1999). Identidades políticas y alteridades históricas. Anuario Antropológico, 97. 
96 / Nicolás PANOtTo

Swartz, M. J., Turner, V. W. y Tuden, A. (1994). Antropología política: una introducción. Revista Alteridades, 8, 101-126.

Starvakakis, Y. (2007). Lacan y lo político. Buenos Aires: Prometeo.

Wynarczyk, H. (2009). Ciudadanos de dos mundos: el movimiento evangélico en la vida pública argentina 1980-2001. Buenos Aires: Unsam. 